\title{
POLÍTICA LINGUÍSTICA EM CONTEXTO DE IMIGRAÇÃO E REFÚGIO: O PLANEJAMENTO DO ENSINO DE PORTUGUÊS COMO LÍNGUA DE ACOLHIMENTO NO ÂMBITO DO DISTRITO FEDERAL
}

\author{
LANGUAGE POLICY IN THE CONTEXT OF IMMIGRATION AND \\ REFUGE: THE PLANNING OF PORTUGUESE EDUCATION AS A HOST \\ LANGUAGE IN THE FEDERAL DISTRICT
}

Lorena Poliana Silva Lopes ${ }^{1}$

Eduardo Melo Rebouças ${ }^{2}$

Umberto Euzebio ${ }^{3}$

\section{Resumo}

O tema norteador deste trabalho é o ensino de Português como língua não-materna a comunidades de imigrantes e refugiados, em caráter de política linguística e de política pública de acolhimento e de cooperação entre Estados-nação. Seu objetivo principal é dar visibilidade aos aspectos Planejamento de curso e Planejamento de aula de um curso de português como língua de acolhimento desenvolvido no Distrito Federal. Algumas questões relevantes são: (i) quais são os agentes comprometidos com esse planejamento?; (ii) qual a importância do planejamento para a implementação de um curso de línguas para refugiados e imigrantes?; e, (iii) quais são os elementos desse planejamento? Metodologicamente, adota-se as concepções teóricas de política linguística e de planejamento de Calvet (2007); Haugen (1964) e Rajagopalan $(2013,2014)$, e as concepções de planejamento de curso e de aula de Almeida Filho $(1997,2011)$ e Oliveira (2015). Como resultados parciais aponta-se que: (i) a elaboração e implementação do PLAc no DF têm sido viabilizadas por meio de parcerias como a do IMDH; (ii) há indícios de que a Secretaria de Estado de Educação do DF passou a se compromissa com essa política de acolhimento.

\section{Palavras-Chave}

Política linguística. Migração forçada. Ensino de línguas. Planejamento de curso. Português como língua de acolhimento.

\begin{abstract}
The guiding theme of this work is the teaching of Portuguese as a non-native language to immigrant and refugee communities, as a language policy and a public policy of reception and cooperation between nation-states. The main objective is to give visibility to the course planning and lesson planning aspects of a Portuguese as a host language course developed in the Federal District. Some relevant questions are: (i) which agents are committed to this planning?; (ii) how important is planning for the implementation of a language course for refugees and immigrants? and (iii) what are the elements of this planning?. Methodologically, we adopted the theoretical conceptions of linguistic policy and planning by Calvet (2007); Haugen (1964) and Rajagopalan (2013, 2014), and the conceptions of course and class planning by Almeida Filho $(1997,2011)$ and Oliveira (2015). As partial results we point out that: (i) the elaboration and implementation of the PLAc in DF has been made possible through partnerships like the one of IMDH; (ii) there are indications that the State Department of Education of the Federal District has now committed itself to this host policy.
\end{abstract}

\section{KEYWORDS}

Linguistic Policy. Forced migration Language teaching. Course planning. Portuguese as the host language.

1 Doutoranda em Estudos de Linguagens pelo Centro Federal de Educação Tecnológica de Minas Gerais.

2 Doutorando em Linguística pela Universidade de Brasília, Professor do Instituto Federal de Brasília.

3 Doutor em Zootecnia pela Universidade Estadual Paulista Júlio de Mesquita Filho, professor da Universidade de Brasília. 


\section{CONSIDERAÇÕES INICIAIS}

Em uma sociedade global, linguística e culturalmente diversificada, onde os fluxos migratórios de pessoas em situações de vulnerabilidades diversas têm se tornado mais densos e visíveis, as mudanças nas conjunturas social, política e econômica dão espaço a novos contextos de ensino e de aprendizagem de línguas não-maternas, dos quais resultam novas abordagens e métodos de ensino (GROSSO, 2010).

Se há uma ou duas décadas o Brasil, assim como outros países do mundo, estava ocupado e preocupado apenas com a migração "de elite", aquela de curto prazo, restrita ao mercado de turismo, ou aquela de médio ou longo prazo, advinda de parcerias comerciais e oportunidades de trabalho especializado e de alta complexidade, já há algum tempo, tem-se sentido a necessidade de se planejar ações responsáveis por tratar da migraşão forçada (ARANTES, DEUSDARÁ e BRENNER, 2016), ou seja, do fluxo migratório de deslocados forçados, de pessoas em situação de refúgio por perseguição política ou religiosa em seus países de origem e, também, de deslocados por questões ambientais.

Por essa razão, tanto as políticas públicas quanto as políticas linguísticas de recepção aos imigrantes, refugiados e solicitantes de refúgio devem ser (re)pensadas, objetivando promover o acesso à língua da comunidade de destino, a fim de contribuir para a interação e integração social desses sujeitos, assim como o acesso aos serviços públicos essenciais e aos direitos humanos.

Sem dúvidas, os sujeitos migrantes possuem demandas importantes e urgentes de natureza diversa, todavia, entendemos que o domínio da língua da comunidade local é uma habilidade primeira, que viabiliza o acesso às outras demandas de modo menos conflituoso e mais digno. Em um contexto de migração forçada, segundo Grosso (2010, p.71), a "proficiência na língua-alvo ultrapassa a motivação turística e acadêmica, interliga-se à realidade socioeconômica e político-cultural em que se encontra".

Orientado por esse entendimento, o tema norteador deste trabalho é o ensino de português como língua não-materna a comunidades de imigrantes e refugiados, em caráter de política linguística e de política pública de acolhimento e de cooperação entre Estados-nação. Nosso objetivo principal é dar visibilidade ao aspecto "planejamento" de cursos de línguas, especificamente de um curso de Português como Língua de Acolhimento (PLAc) desenvolvido no Distrito Federal e destinado a refugiados e imigrantes que têm buscado o Brasil como país de destino.

Para tanto, algumas questões que nortearão nossas discussões teóricas sobre o planejamento do ensino de PLAc no âmbito do Distrito Federal e que podemos destacar neste momento são: (i) quais são os agentes comprometidos com esse planejamento?; (ii) qual a importância do planejamento para a implementação de um curso de línguas para refugiados e imigrantes?; e (iii) quais são os elementos desse planejamento, uma vez que este é entendido como fundamental no contexto linguístico-pedagógico de PLAc?

\section{FUNDAMENTAÇÃO TEÓRICO-METODOLÓGICA: O PLANEJAMENTO DE ENSINO}

Ao tomarmos como tema o ensino de português como língua não-materna a comunidades de imigrantes e refugiados, em caráter de acolhimento, adentramos um espaço de conflitos, redirecionamentos, surgimento e/ou reformulação de alguns conceitos e termos, como, por exemplo, 
‘acolhimento' ou 'língua de acolhimento'. Concordamos que língua de acolhimento “é uma perspectiva discursiva que envolve concepções sociopolíticas por parte de quem acolhe, e direciona as práticas pedagógicas a fim de se adequar às novas demandas da sociedade. Dessa forma, é um campo em contínua construção teórica, política e social” (EUZEBIO, REBOUÇAS e LOPES, 2018, p.83).

Se, como afirmamos, a língua de acolhimento está em continua construção, como ela se realiza teórica, política e socialmente? Para essa reflexão, precisamos voltar um passo e rever o contexto brasileiro no que diz respeito à política linguística, área que seria responsável por dar atenção ou silenciar esse refazimento conceitual e político do acesso linguístico. Segundo Lopes,

ainda que se tenham aberto espaço para a disciplina (Política linguística) no século XX, é somente no século XXI, que o Estado tem, de fato, tomado para si responsabilidade sobre as pautas das políticas linguísticas, muito em resposta a movimentos sociais que hoje têm lutado veementemente pelos seus direitos e necessidades linguísticas. Além disso, diante de uma ascensão política e econômica (muito em razão dos blocos econômicos), o Estado, hoje, tem grandes interesses na internacionalização da língua portuguesa, o que o leva a dar importância ao tema/disciplina (LOPES, 2018, p.53).

De acordo com o Comitê Nacional para os Refugiados (CONARE), o Brasil possui e pratica uma política de acolbimento de refugiados e esta avançou significativamente nas últimas duas décadas. Interessa-nos saber até que ponto essa política de acolhimento, pois, é constituída por um planejamento de acolhimento linguístico, aspecto essencialmente ligado ao reconhecimento e à importância dessa demanda enquanto política linguística. Conforme Lopes aponta, a atenção dada à política linguística é algo recente no Brasil e, em se tratando de grupos minoritários, podemos inferir que seja um desafio ainda maior.

A política linguística pode ser observada a partir de diferentes perspectivas, como disciplina, como campo do saber, como setor, como instrumento, como secretaria. Talvez caiba a nós olharmos a política linguística como ação política e planejamento civil e institucional, uma vez que ela pode ser realizada pelo Estado ou pela sociedade civil: "no contexto da política linguística há muitos exemplos de decisões tomadas e implementadas tanto no sentido de cima para baixo (top down), como no sentido inverso, isto é, de baixo para cima (bottom up)" (RAJAGOPALAN, 2013, p.36), apesar de, nos anos 50, o termo Política linguística dizer respeito a atividades realizadas exclusivamente âmbito da esfera do poder - do Estado.

Em Calvet encontramos uma explicação mais clara do que vem a ser política linguística e da sua relação com o planejamento linguístico. Segundo ele, nos estudos relativos à gestão linguística,

consideram-se uma situação sociolinguística inicial (S1), que depois de analisada é considerada como não satisfatória, e a situação que se deseja alcançar (S2). A definição das diferenças entre S1 e S2 constitui o campo de intervenção da política linguística, e o problema de como passar de S1 para S2 é o domínio do planejamento linguístico (CALVET, 2007, p.61).

Assim, política linguística é "a determinação das grandes decisões referentes às relações entre as línguas e a sociedade" e planejamento linguístico é “a sua implementação" (CALVET, 2007, p.11). Tais conceitos não são distantes da nossa realidade se pensarmos que o planejamento é uma atividade presente em quase tudo da nossa vida pessoal e profissional. No âmbito da política e da 
Linguística ou da gestão de línguas isso não é diferente: em todas elas há a necessidade de um planejamento. Haugen nos lembra exatamente disso,

o planejamento é uma atividade humana decorrente da necessidade de se encontrar uma solução para um problema. Ele pode ser completamente informal e ad hoc, mas pode também ser organizado e deliberado. Pode ser executado por indivíduos particulares ou ser oficial (HAUGEN, 1964 apud Calvet, 2007, p.21, grifo nosso).

Nesse sentido, sempre que surge uma nova necessidade, independente da sua natureza, ou um novo problema, surge também a necessidade de um planejamento. Como mencionado, o contexto de migração forçada como temos visto no Brasil é recente, de ocorrência na última década.

Essa realidade demanda a construção de novas políticas linguísticas e de políticas de integração social. São as especificidades desse público que justificam [...] a reflexão, o planejamento e a reformulação de práticas pedagógicas que nos revelam, na verdade, não só concepções e posicionamentos linguísticos e pedagógicos, mas, também, políticos e sociais (EUZEBIO, REBOUÇAS e LOPES, 2018, p.60).

As palavras de Almeida Filho vêm corroborar com essa compreensão. Como bem retoma Viana:

A necessidade de um planejamento pode ocorrer em diferentes situações educacionais. Almeida Filho (1996) distingue duas situações, a saber: 'onde já existem planejamentos (inadequados em alguma medida) ou em situações novas para as quais o planejamento é um pré-requisito para a implementação de um processo de ensino-aprendizagem' (VIANA, 1997, p.34, grifo nosso).

No caso do ensino de Português como Língua de Acolhimento (PLAc), o contexto de migração forçada que se instalou no Brasil na última década tem se configurado como uma "situação nova", cuja especificidade tem sido determinante para o surgimento de novos contextos de ensino e de aprendizagem de língua não-materna, portanto, de planejamento de cursos de língua portuguesa para migrantes. Não por acaso, há algum tempo, Viana já apontava que "o planejamento de um curso de línguas, a rigor, constitui-se como um processo reflexivo sobre e para a dinâmica de outro processo: o de ensino/aprendizagem de línguas" (VIANA, 1997, p. 29, grifo nosso), e a abordagem é um elemento crucial para o delineamento de suas decisões.

O planejamento de ensino de línguas para públicos específicos exige em sua composição, portanto, um planejamento de curso, que estaria mais voltado às questões macro e estrutural, e um planejamento de aula, que estaria mais voltado às questões micro, como o conteúdo efetivamente ensinado em cada aula. Para Oliveira, "o planejamento da aula e o gerenciamento da sala de aula constituem-se em conjuntos de ações essenciais para o ensino" (OLIVEIRA, 2015, p.18, grifo nosso), os quais o autor chama de logística.

De modo mais detalhado, o 'planejamento de curso' é orientado por uma 'abordagem' e composto por uma 'gama de elementos que dão forma ao curso de línguas' e, mais do que isso, que possibilitam a sua existência e desenvolvimento. Almeida Filho $(1997,2011)$ postula que a abordagem ou a filosofia didático-pedagógica do ensino, a qual possui métodos e técnicas, seria a "força que orienta, e portanto caracteriza em essência, todo um processo específico de ensino de língua". Nesse sentido, "essa força advém das competências implícita (básica), teórica, aplicada e 
(meta) profissional do professor ou de quaisquer outros agentes ativos de ensino, tais como autores de LDs [Livros Didáticos], planejadores de cursos, produtores de instrumentos de avaliação, pais, tutores, etc" (ALMEIDA FILHO, 1997, p.17).

No ensino de português como língua não-materna para migrantes e refugiados, o curso é orientado pela perspectiva de língua de acolhimento, a qual "extrapola os saberes puramente linguísticos, envolve as dimensões interdisciplinar, intercultural, social, psicossocial e política" (EUZEBIO, REBOUÇAS e LOPES, 2018, p.83). A perspectiva do acolhimento, portanto, representa a abordagem ou filosofia didático-pedagógica que deve orientar o planejamento de um curso. Sem essa consideração o seu enquadre é outro e não pode ser caracterizado como de um curso de acolhimento.

Além da abordagem, outros elementos que constituem o planejamento de curso, segundo Viana (1997), são:

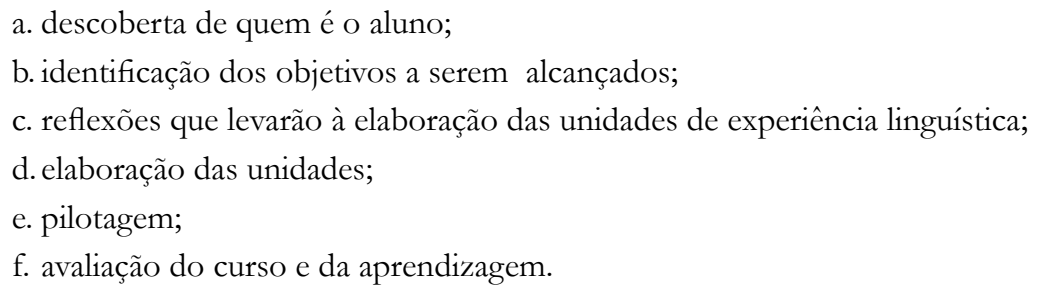

Para o contexto de língua de acolhimento, entendendo-a como uma política linguística efetivada por civis ou grupos de pesquisa e extensão, portanto, não realizada diretamente pelo Estado, é relevante acrescentar à lista acima outros elementos como: (vii) identificação do agente: quem ou qual instituição é responsável pela elaboração e planejamento do curso; (viii) definição de quais recursos financeiros, materiais e humanos serão mobilizados para o planejamento e a aplicação; e (ix) indicação de onde se realizará o curso. Por não se tratar de um planejamento de ensino dentro de um centro de línguas, onde se prevê a disponibilidade do espaço físico e dos recursos humanos e materiais, por exemplo, tais questões devem ser enfrentadas desde o início do processo de planejamento, sem as quais não há como prosseguir para o planejamento de aula.

Por fim, em um nível micro, temos outros elementos que constituem o 'planejamento de aula', os quais, segundo Oliveira (2015) são:

\footnotetext{
i. quem são os alunos e por que estão ali;

ii. materiais: o que os alunos precisam aprender hoje e a que precisam ser expostos hoje. A seguir, é que o professor se pergunta "o que vou ensinar hoje";

iii. metodologia;

iv. plano de aula;

v. gerenciamento de sala de aula: fala do professor, uso da língua materna dos alunos e monitoramento.
}

A partir das perspectivas teóricas apresentadas e discussões estabelecidas até o momento, demonstramos que o ensino de português como língua de acolhimento é uma área nova e especializada, reconhecida a partir de uma visão política de cooperação e de reintegração social compartilhada, cujas demandas envolvem o planejamento de curso e o planejamento de aula enquanto política de acolhimento e de justiça social. 
No esquema abaixo, sintetizamos a atividade de planejamento a partir dos quatro eixos subjacentes:

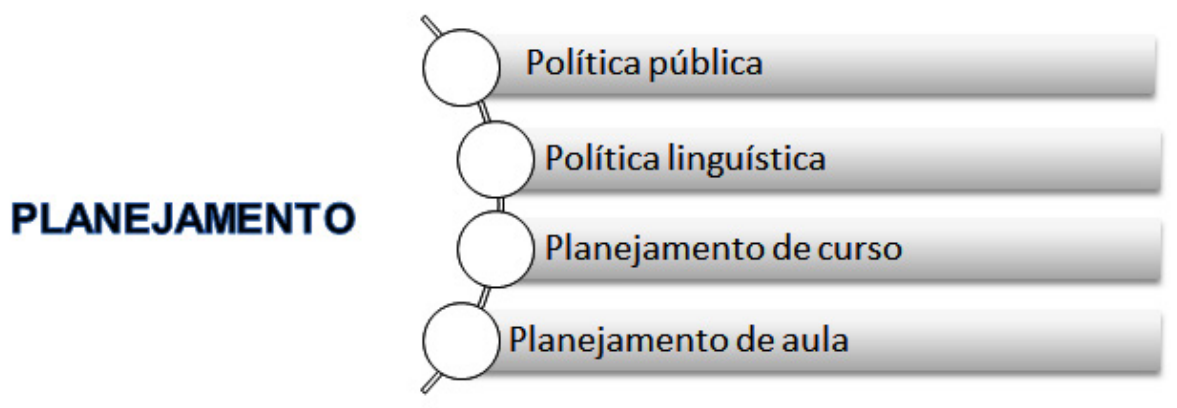

Figura 1. Eixos subjacentes ao Planejamento.

Fonte: Elaborado pelos autores.

Apresentamos na seção seguinte como esse planejamento foi requerido pela realidade local do Distrito Federal e como foi desenvolvido por professores e estudantes por meio de um projeto de extensão da Universidade de Brasília - UnB. Abordaremos os quatro eixos do planejamento, bem como os elementos que o compõem, e apresentaremos um relato de experiência, em que os dados e as informações utilizadas na contextualização e nas análises são compartilhados entre os membros do grupo, em reuniões, conversas, práticas de planejamento e de ensino, e advém de experiências de nosso cotidiano no Projeto.

\section{O planejamento de curso e o planejamento de aula de PlAc no Distrito FEDERAL}

Nesta seção, apresentaremos uma discussão sobre o planejamento do ensino de Português como Língua de Acolhimento a imigrantes e refugiados, no âmbito do Distrito Federal, compreendendo-o como política pública e política linguística. Tal planejamento envolve, conforme vimos em nosso construto teórico, o planejamento de curso e o planejamento de aula.

Antes, porém, de comentarmos cada elemento do planejamento, se faz necessário refletir um pouco mais acerca do acolhimento como política pública. Nos últimos anos, cada vez mais brasileiros têm conhecido ou pelo menos visto migrantes nos vários espaços sociais pelos quais passamos. Muitos brasileiros, também, já devem ter participado, em algum momento da vida, de modo informal, de uma conversa sobre migração, seja a migração de elite, seja a migração forçada (mesmo sem conhecerem esses termos e conceitos). Tais situações são importantes, pois nos levam aos fatos: o fenômeno migratório sempre existiu no mundo e hoje temos tido a oportunidade de conhecer várias faces dele.

A migração forçada, como mencionado, diz respeito ao fluxo migratório de deslocados forçados, de apátridas e de pessoas em situação de refúgio por perseguição política ou religiosa em seus países de origem. Diferente do que o senso comum costuma interpretar, esse tipo de migração não é ilegal, tampouco irregular. O Brasil é signatário das principais convenções e tratados sobre os refugiados, possui as leis nacionais 9474/1997 e 13.445/2017, que dispõem e regulamentam a migração, e reconhece a Declaração Universal dos Direitos Humanos (1948). Conhecer tais documentos é importante, porque contribuem para a diminuição da resistência ao acolhimento à 
promoção de políticas públicas específicas por parte da sociedade civil, além de responsabilizar o Estado pela elaboração dessas políticas e pelo suprimento dos direitos humanos básicos.

Nesse sentido, Lussi (2015, p.136) enfatiza que as políticas migratórias não se limitam a pensar "quem pode ou não entrar num país", mas como garantir que os estrangeiros que aqui passam a residir tenham acesso às políticas "universais" do país (direitos como educação e saúde). Além disso, essas políticas devem pensar em soluções para problemas ou demandas específicas da comunidade de migrantes. Ainda segundo a autora,

Políticas públicas para migrantes podem fortalecer as desigualdades, enquanto a inclusão da população migrante e refugiada nas políticas públicas pensadas em uma perspectiva integral e transversal favorece a integração e a prevenção de violações de direitos. Desigualdade não se combate com igualdade; se previne com equidade (LUSSI, 2015, p.136).

Assim, entendemos que pensar em políticas públicas de inclusão e integração de imigrantes à comunidade acolhedora, bem como planejar políticas linguísticas, são tarefas de suma importância, inicialmente de responsabilidade do Estado, mas também, de responsabilidade da sociedade, uma vez que tais ações previnem a violação de direitos e criam condições de vida digna aos sujeitos migrantes. Conforme o Relatório Mundial da Migração 2013 - RMM (World Migration Report 2013 - WMR, p.23-27), elaborado pela Organização Internacional para as Migrações - OIM/ONU, há quatro tópicos essenciais que indicam pistas para políticas públicas inclusivas:

1. Os imigrantes como elemento central do debate: foco no sujeito - identidade, experiências e direitos humanos;

2. Desenvolvimento significa bem-estar humano: a compreensão de que desenvolvimento significa garantir a integração e a inclusão dos migrantes na sociedade civil, evitando a sua criminalização e vulnerabilização;

3. Migração não é apenas um fenômeno norte-sul: a migração é um fenômeno humano, natural, apesar de às vezes ser em caráter emergencial; a migração sempre existiu e continuará existindo.

4. A migração promove o desenvolvimento humano, mas ainda existem numerosos migrantes que não conseguem atingir um nível de bem-estar satisfatório: aos migrantes falta uma política de inserção no mercado de trabalho, de modo a evitar a tendência de destiná-los aos subempregos por sua condição de migrante.

Em suma, esse relatório evidencia que políticas públicas inclusivas para migrantes devem ser pautadas em uma visão de desenvolvimento humano integral e de senso de responsabilidade dos e entre países. Além disso, vale ressaltar que essas mesmas políticas públicas inclusivas precisam considerar a heterogeneidade desse público, sendo que suas nacionalidades e identidades culturais são diversas. Planejar políticas públicas nesse contexto é, necessariamente, intervir em situações de conflito e prevenir a criminalização e a vulnerabilização dos sujeitos migrantes. Lussi (2015, p.136) alerta que "as desigualdades podem ser registradas nas mais variadas realidades, tais como em relações interpessoais ou profissionais, no acesso a serviços ou no reconhecimento de direitos".

Importando-se com essas questões da migração forçada e visando à construção de uma política linguística inclusiva, comprometida com o desenvolvimento humano integral de migrantes, o Projeto "Interdisciplinaridade para o acolhimento e inserção de refugiados e imigrantes do Haiti à 
cultura brasileira e ao português do Brasil", recentemente renomeado para "Projeto de Pesquisa: Educação e Cultura para indígena, refugiado e imigrante haitiano no Distrito Federal", surgiu em 2014 como uma ação que atua na lacuna do Estado, uma vez que este ainda não conseguiu se articular para fornecer o acesso linguístico a essa comunidade.

Sabemos que em outros países, como Portugal, Canadá e Alemanha há uma prática de acolhimento linguístico oferecido a todos os migrantes que têm esses países como destino. O Brasil, apesar de ter centros culturais distribuídos em países de diversas regiões do mundo, apresenta uma dificuldade em criar esse tipo ação, além de não ter aberto um centro dessa natureza ou similar em território brasileiro. Em seu Caderno de Debates (2017), o Instituto de Migrações e Direitos Humanos - IMDH evidencia a importância do planejamento de cursos de língua portuguesa destinados à comunidade migrante e refugiada:

\footnotetext{
Aprender português é um elemento essencial para facilitar a integração local de migrantes e refugiados no Brasil. Diante da falta de políticas públicas sistemáticas nesta área, voluntários, organizações da sociedade civil e universidades se unem para superar as limitações orçamentárias, de pessoal e de logística. Neste contexto, os projetos de extensão de diversas IES têm dado valiosa contribuição, viabilizando, de imediato, a oferta de aulas e outras atividades correlatas. Ao mesmo tempo, as próprias IES desempenham papel central na produção de insumos para elaboração dessas políticas públicas, notadamente por meio do desenvolvimento de pesquisas, material didático e formação de professores (COURY \& ROVERY, 2017, p.115).
}

Convergindo com essas informações, o Projeto de Pesquisa: Educação e Cultura para indígena, refugiado e imigrante haitiano no Distrito Federal se apresenta como um exemplo de projeto de atenção aos migrantes e refugiados, fomentado por uma IES, a Universidade de Brasília, e desenvolvido por um professor da instituição e por graduandos voluntários de cursos da área de humanas, principalmente do curso de Letras. Como elucidado acima, esse projeto se comporta como uma política pública inclusiva e se ocupa do fornecimento de um curso de língua portuguesa às comunidades migrantes que apresentam vulnerabilidades, consciente de que, apesar das Leis mencionadas, o Estado tem apresentado deficiência na consolidação de uma política linguística para esse novo fluxo migratório. Dito isso, como o Projeto tem planejado uma política linguística?

A partir das questões e dos elementos do planejamento de curso e do planejamento de aula levantados no aporte teórico, a seguir, procuraremos mostrar a complexidade do planejamento e da implementação de uma política linguística de acolhimento.

\section{Planejamento de curso}

Como explicitado anteriormente, os estudos postulam que o planejamento de curso é orientado por uma abordagem e composto por uma gama de elementos que dão forma ao curso de línguas e, mais do que isso, que possibilitam a sua existência e o seu desenvolvimento. Até aqui, enquadramos o curso de língua portuguesa ofertado pelo Projeto como uma política pública inclusiva sob a abordagem do acolhimento, entendendo que essa perspectiva é singular - nem todos os cursos de línguas se propõem a ser de acolhimento.

Todavia, no planejamento desse tipo de curso há, ainda, outras fundamentações linguístico-pedagógicas que se apresentam como necessárias para se delinear metas e objetivos. No caso do 
curso em questão, há uma liberdade pedagógica por parte dos docentes e dos planejadores de materiais didáticos, aspecto que veremos de forma mais aprofundada no item Planejamento de aula, mas também há suporte linguístico-teórico partilhado por todos os participantes desde a concepção do curso, que é a Abordagem Sociointeracional, embasada na Teoria Sociocultural (PAIVA, 2014) (também não podemos afirmar que todos os cursos de acolhimento possuem essa base teórica).

A Abordagem Sociointeracional (episteme sociointeracionista aplicada ao contexto de ensino de línguas) foi desenvolvida a partir das ideias de Vigotski, e entende que a relação linguística interpessoal "vai além do ato de comunicar, pois a língua é concebida na perspectiva da ação: quem fala age e provoca em seu interlocutor uma ação, estabelecendo, assim, um ato interacional” (RAMOS, 2017, p.43).

O planejamento do curso possui alguns princípios, como:

- Promover uma política de acolhimento a migrantes e refugiados e uma política de cooperação e paz entre estados-nação;

- Promover o acesso linguístico a esse público-alvo específico para viabilização de acesso aos direitos e deveres do migrante, previsto em Lei (Lei de Migração 13.445/2017; Lei do Refúgio 9.474/97) e na Declaração Universal dos Direitos Humanos (1948);

- Promover a inclusão e a integração linguística e cultural dos migrantes à comunidade local (brasiliense);

- Ensinar a língua priorizando habilidades de compreensão oral e expressão oral, objetivando o desenvolvimento de competências para a interação linguística.

$\mathrm{Na}$ prática, tais princípios são materializados no planejamento de curso e no planejamento de aula. Vejamos, nesta seção, algumas características do planejamento de curso, conforme os elementos elencados por Viana (1997):

(i) Descoberta de quem é o aluno: a descoberta de quem é o aluno se atrela à descoberta da existência de um grande fluxo migratório de haitianos, sendo a maioria deles portadores de visto humanitário, no Distrito Federal, no ano de 2014. A partir da compreensão de que esse público necessitava aprender a língua portuguesa e da identificação de que não havia um suporte do Estado nesse sentido, pessoas civis iniciaram esse serviço e, em seguida, a UnB, representada por um docente, tomou essa responsabilidade por meio do instrumento de políticas públicas "projeto de extensão" (hoje, projeto de pesquisa).

Esse histórico, entretanto, não impediu e não impede que imigrantes de outras nacionalidades possam ser beneficiados por esse serviço, necessitando, apenas, de fazerem parte do contexto de migração forçada, tendo em vista as peculiaridades e especificidades de ensino. Isso significa que imigrantes intercambistas, por exemplo, não fazem parte do escopo discente atendido.

(ii) Identificação dos objetivos a serem alcançados: os objetivos principais desse planejamento de curso são: a promoção e a viabilização do acesso ao aprendizado da língua portuguesa como língua não-materna, por meio da estruturação do curso de língua; a estruturação desse curso firmado na noção de acolhimento e de política de inclusão e inserção social; o ensino da língua priorizando as habilidades de compreensão oral e expressão oral, com foco no desenvolvimento de competências de interação linguística para fins emergentes, como a interação imediata com brasileiros em situações de pedido de informação, de aluguel de imóveis, de compreensão dos seus 
direitos e deveres em território nacional, entre outras situações do dia a dia no Brasil; e a inserção cultural e linguística desses sujeitos na comunidade local, de modo que também possam interagir com brasileiros em situações de lazer e de intercâmbio cultural.

Espera-se que, por meio das aulas, os migrantes consigam compreender a lógica de funcionamento da nossa sociedade e as nossas motivações para determinados hábitos, costumes e práticas sociais. Por exemplo: quando uma pessoa está passando mal e precisa de atendimento médico, o que ela pode fazer? Com questionamentos como esse mostramos aos migrantes quais são os serviços públicos disponíveis em nosso país, onde estão localizados, quais são os meios mais adequados para acessá-los e quem pode acessá-los.

(iii) Reflexões que levarão à elaboração das unidades de experiência linguística: em convergência com os principais objetivos do curso, descritos no item anterior, as questões seguintes se apresentam como essenciais a esse planejamento: (i) quais são os objetivos e as justificativas para o planejamento de um curso de língua na perspectiva de acolhimento? Esse tipo de curso somente se justifica por meio da existência de uma migração forçada no Brasil e das demandas específicas advindas dela; (ii) quais são essas demandas específicas e como elas passam pela experiência linguística? Durante esses anos de trabalho, identificamos que, sobretudo, essas pessoas precisam se sentir emocionalmente incluídas e aceitas em nossa sociedade (na cidade onde se encontram), e esse processo se inicia na oportunidade de frequentar um curso de língua portuguesa. Isso, primeiro, porque ao saberem que há um curso disponível gratuitamente para elas, sem dúvidas há a compreensão de que "alguém se importa com elas aqui”, segundo, porque frequentar um curso para migrantes significa conviver com pessoas que também passaram por momentos difíceis e conflituosos, como o próprio ato de migrar. Dessa forma, nesse ambiente, além de aprenderem a língua local, uma ferramenta de enfrentamento das adversidades de uma vida em outro país, em outra sociedade, podem intercambiar experiências e estratégias de superação e de desenvolvimento de vida na nova cidade, na nova realidade linguístico-político-social.

Identificamos, também, que os migrantes precisam se sentir seguros e autônomos em relação às burocracias e às responsabilidades formais do dia a dia, as quais, em parte, são específicas de quem está em situação de imigração ou refúgio, como a abertura de processos na Polícia Federal, e, em parte, são comuns a qualquer pessoa que resida no Brasil.

Com o objetivo de proporcionar aos discentes participantes do projeto o desenvolvimento dessa segurança e autonomia, o conteúdo do curso se preocupa com a abordagem das informações que se apresentam como essenciais para os migrantes e que, sabemos, não são de fácil acesso em setores públicos nem em contatos com vizinhos ou desconhecidos na rua, por exemplo. A sociedade civil, de modo geral, não está apta para informar à comunidade migrante os seus direitos e os seus deveres nem onde/como acessá-los.

No nível macro, portanto, a abordagem do acolhimento, os objetivos e as justificativas para o planejamento do curso são os elementos que orientam a abordagem linguístico-pedagógica adotada. No nível micro, a combinação desses elementos orienta a seleção dos métodos e das técnicas, bem como dos conteúdos e dos materiais de aula.

(iv) Elaboração das unidades: no planejamento desse curso de acolhimento, elaboramos as unidades a partir de uma metodologia de "oficinas", em que cada aula possui início, desenvol- 
vimento e fim num período de uma aula de três horas. Isso, porque as experiências e as pesquisas sobre o fluxo migratório têm revelado que é significativa a mudança de cidade ou de Estado nos primeiros meses ou anos em que a pessoa é migrante. Alguns fatores que determinam esse fluxo contínuo de mudança é a oferta de empregos e a possibilidade de melhoria na condição de vida.

Para um migrante, não é viável permanecer em uma cidade que não está lhe trazendo o retorno mínimo esperado, como a condição financeira básica para pagar uma moradia e a alimentação diária. Frequentar um curso de língua portuguesa, ainda que seja relevante para a sua autonomia, não é um fator determinante para que ele não migre novamente. Assim, para que haja aprendizado, independentemente de quando a pessoa entrou ou saiu do curso, ou de quantas aulas frequentou, optamos por aulas não sequenciais, as quais chamamos de oficinas, comprometidas com o que os alunos presentes em cada aula precisam ou sinalizam que querem ou necessitam aprender.

Por essas razões contextuais, o processo de elaboração das unidades do curso é orientado pela metodologia de aula por oficinas, e a responsabilidade dessa elaboração é dos professores atuantes no curso, conforme escala de regência para cada aula, e tem em vista as alterações na composição discente da turma: ingresso e saída de alunos. Tem-se experienciado a necessidade constante de adaptação dos planos de aula, haja vista as especificidades do contexto de PLAc, e de atenção a mais de uma demanda de conteúdo no decorrer da aula.

Para isso, o planejamento de curso em nível macro precisa prever a capacitação do corpo docente para esse modo ou metodologia de trabalho (visto que cursos de línguas costumam trabalhar por módulos e conteúdos sequenciados), exigindo-se sensibilidade para a realidade contextual da turma e do próprio ensino de português como língua de acolhimento.

(v) Pilotagem: no planejamento de um curso de acolhimento, podemos pensar na pilotagem como um período de aulas em que se observa o seu grau de efetividade para a comunidade migrante. Geralmente esse período tem duração de umas quatro aulas e ocorre quando voltamos de algum período de recesso, momento em que precisamos aguardar o retorno dos antigos alunos e a chegada de novos alunos, além de identificarmos os novos dados do fluxo migratório e informações como onde está esse fluxo e se ele sofreu alteração dentro da cidade onde atuamos.

Esse tipo de informações é relevante porque atuamos nas cidades onde há maior registro de moradores migrantes no DF, com o intuito de viabilizar a participação deles nas aulas, diminuindo os custos individuais com transporte e o tempo gasto com deslocamento. Ao longo desses anos, o curso já precisou mudar de localização algumas vezes, e a identificação desse tipo de demanda só foi possível a partir dessas informações e constatações durante o período letivo: se não há alunos em determinada localidade, mesmo que seja onde se estava atuando no período anterior, então é oportuno que se reorganize essa atividade em outra localidade, preferencialmente em uma que possua registro de residentes migrantes.

(vi) Avaliação do curso e da aprendizagem: em nosso planejamento, a avaliação do curso ocorre ao longo do semestre letivo, em nossas reuniões semanais do projeto de extensão, das quais participam o coordenador e os extensionistas. Nessas reuniões, todos têm a oportunidade de relatar e comentar o que ocorreu na semana anterior, com a finalidade de compartilhar informações relevantes para o andamento do curso, mas também para reflexão crítica e avaliação da prática pedagógica e da adequação do curso ao momento presente. 
Além dessa avaliação interna, há, sem dúvida, por meio da interação nas aulas, uma avaliação do curso que parte dos próprios alunos, por exemplo, quando eles opinam sobre o andamento das oficinas, sobre os conteúdos abordados e sobre a adequação do horário em que as oficinas são realizadas em relação ao contexto pessoal deles. Esse contato com o aluno e a atenção ao seu feedback permitem desenvolver mecanismos de avaliação, de percepção, de acolhimento, embasados na perspectiva holística e transversal da Escuta Sensível (BARBIER, 1998, 2007), e, assim como Cancherini, Franco e Pontes (2012, p.5), consideramos que ouvir para compreender exige uma sensibilidade maior em relação ao outro, dificilmente conseguida sem que se crie espaço para o diálogo autêntico.

No curso, não se utilizam provas ou exames como instrumentos de avaliação. A avaliação da aprendizagem ocorre em cada oficina, por parte do professor responsável por sua aplicação, o qual percebe os avanços linguísticos do aluno com relação a aulas anteriores e, em especial, identifica o que foi apre(e)ndido especificamente em cada aula-oficina: o que o aluno não conhecia ou apresentava dificuldade no momento inicial da aula e que, a partir do desenvolvimento da oficina, passou a conhecer e/ou apresentou avanços linguísticos com relação a conhecimentos prévios (adquiridos em seu cotidiano linguístico-social no país ou por meio da participação nas oficinas desenvolvidas pelo Projeto).

Consideramos que, em especial, no contexto de língua de acolhimento, aos elementos constituintes do planejamento de curso, apontados por Viana (1997), podemos acrescer:

(vii) Identificação do agente: o planejamento desse curso não seria possível sem que houvesse uma rede de agentes, comprometida com a sua criação e realização. A instituição diretamente responsável pelo projeto de extensão e por suas ações é a Universidade de Brasília (UnB), sob a coordenação do professor Umberto Euzébio.

Todavia, não podemos deixar de mencionar que a realização do projeto sempre contou com parceiros, dentre eles o Instituto de Migrações e Direitos Humanos (IMDH), por meio da Irmã Rosita Milesi, que nos apoiou com o empréstimo de um local para a realização das aulas em uma das cidades onde atuamos e com o direcionamento dos migrantes e refugiados que buscam atendimento no instituto ao curso de língua portuguesa. Outro agente apoiador importante foi o governo do Distrito Federal, através do DFTrans, autarquia que gere e opera o Sistema de Transporte Público Coletivo do DF, e que forneceu, durante um tempo determinado, passagens gratuitas (passe-livre) aos alunos do curso que residiam em outra cidade. Desde 2017 não há mais essa parceria, por decisão unilateral do DFTrans.

Além desses, temos há algum tempo uma sinalização da Secretaria de Estado de Educação do Distrito Federal (SEEDF) de que haverá maiores esforços dela para que haja uma política de acolhimento na Educação, visto que há um número significativo de estudantes migrantes matriculados em escolas públicas do DF. Até o momento, essa Secretaria nos apoiou cedendo, temporariamente, autorização para uso de salas de escolas públicas para a realização das aulas de português em algumas localidades.

Embora esses sejam apoiadores efetivos, cabe considerar, também, que há outros agentes que, indiretamente, influenciaram na criação e na continuidade dessa ação, por possuírem como missão e trabalho a migração, como a Acnur - Agência da ONU para refugiados, e o Conare, or- 
ganismo público responsável por receber as solicitações de refúgio e conceder ou não o reconhecimento às solicitações recebidas. Instituições como essas lidam com a migração e com as políticas públicas para migrantes diariamente, atuam sob as leis e regimentos que tratam dos migrantes e, principalmente, afirmam abertamente, em seus sites e em alguns documentos, que agem orientadas por uma política de acolhimento e de cooperação e paz entre estados-nação. Esta, como já mencionado, também é a nossa fundamentação para realizar um trabalho especializado na comunidade migrante, especificamente, na comunidade constituída por migração forçada.

(viii) Definição de quais recursos financeiros, materiais e humanos serão mobilizados para o planejamento e a aplicação: o planejamento desse curso e, cremos, de outros cursos de acolhimento, não contam com recursos financeiros ou contam com recursos bastante limitados. Até hoje, atuamos basicamente sem recurso. O projeto não conta com fomentos de pesquisa nem com recursos privados.

Os professores do projeto são alunos de graduação e de pós-graduação da Universidade de Brasília, que participam da extensão formalmente como voluntários. Os materiais didático-pedagógicos são elaborados pelos próprios professores do projeto e em caso de impressos e xerox, ou compra de outros materiais, os professores custeiam os gastos com recursos particulares.

Os espaços físicos onde ocorrem as aulas são cedidos de forma gratuita, temporariamente, ao projeto, sendo estes, por exemplo, salas de escolas públicas ou salas de centros comunitários religiosos.

(ix) Definição de onde e quando se realizará o curso: como vimos, o público-alvo é um fator determinante e orientador de todo o planejamento de curso. Assim, a definição da cidade de funcionamento do curso é fundamentada pela identificação das regiões em que há os maiores registros de migrantes em todo o Distrito Federal. Parte do atendimento é feito pelo curso em questão e parte é feito por outras instituições públicas ou privadas e por civis, visto que há demanda em várias localidades e que o projeto de extensão não consegue atender a todas.

Nesse modelo de curso que vem sendo delineado, buscamos atender aos migrantes na região onde eles moram (em maioria), evitando a geração de gastos financeiros por parte deles e proporcionando a otimização do tempo destinado a essa atividade. Preocupamo-nos, também, como o horário de realização das aulas, pois este precisa atender ao maior número de alunos possível quem define o horário também é o público-alvo.

\section{Planejamento de aula}

Nesta seção, apresentaremos a análise do planejamento de aula, conforme os elementos levantados por Oliveira (2015) e anteriormente descritos: quem são os alunos e porque estão alí; materiais; metodologia; plano de aula; gerenciamento de sala de aula. Vejamos, portanto, cada elemento, respectivamente.

(i) Quem são os alunos e por que estão alí? Sabemos que necessariamente o público-alvo é formado por refugiados, solicitantes de refúgio e migrantes com visto humanitário. Entretanto, para o planejamento do nível micro, o professor precisa saber mais do que isso para desenvolver a sensibilidade necessária para lidar com os alunos e para elaborar materiais adequados ao seu público. 
Saber informações como há quanto tempo o migrante está no Brasil, se ele já fez algum curso de língua portuguesa, que língua ele domina ou possui algum tipo de conhecimento, e por que ele precisou migrar, podem auxiliar os professores na escolha e elaboração de materiais e de conteúdos para as oficinas/aulas, bem como na compreensão do motivo pelo qual o migrante está no Brasil. Por vezes, essas pessoas não escolhem o Brasil como país de destino porque "sempre desejaram vir para cá”, mas porque viram na migração uma oportunidade, talvez a única, de viver com dignidade.

Por outro lado, saber o porquê de o aluno estar no curso é de grande importância, pois a base desse trabalho são as motivações, as expectativas e, principalmente, as necessidades de aprendizado e de inserção cultural e social do migrante que movem e direcionam o curso.

(ii) Materiais: As questões norteadoras para a elaboração e a escolha de materiais e de conteúdos, indicadas por Oliveira (2015), correspondem diretamente ao processo empregado no contexto de ensino de língua aqui analisado. Por considerarmos que um dos principais objetivos do curso é o suprimento das demandas linguísticas trazidas pelos próprios alunos, tomamos como ação docente a realização do seguinte questionamento: "o que os alunos precisam aprender hoje e a que precisam ser expostos hoje?”. Após esse diagnóstico é que o professor se pergunta “o que vou ensinar hoje?".

Nesse sentido, há o compromisso com a escolha de conteúdos e de materiais orientado pelas demandas e necessidades dos alunos naquele momento da aula, sempre pensando em situações linguísticas das práticas sociais do dia a dia e valorizando conteúdos de caráter informativo, como os de política, mobilidade e cultura. Por esses aspectos, nesse planejamento não há obrigatoriamente a adoção de um livro didático, portanto, os professores também são responsáveis pela seleção de materiais e de recursos, a depender da disponibilidade local, e pela criação de atividades orais e escritas, como dinâmicas, jogos e atividades impressas.

Para que haja a elaboração desses materiais, o professor precisa ter um nível mínimo de preparo antes do momento da aula e alguns materiais à sua disposição. Na prática, os professores elaboram um plano prévio, com uma proposta composta por temática, conteúdo e material didático a ser trabalhado, baseando-se nos conhecimentos e na experiência que ele já tem com a turma à qual seu trabalho se destinará. No momento da aula, efetivamente, esse planejamento tende a ser alterado, repensado, em parte ou 'completamente', a partir das demandas que surgem desde o início da aula. Assim, de modo geral, o planejamento já prevê o replanejamento advindo de demandas imediatas da aula, assim como os materiais selecionados também viabilizam novas abordagens e usos.

(iii) Metodologia: como previamente mencionado, no planejamento do curso em questão, há uma liberdade pedagógica por parte dos professores e planejadores de materiais didáticos e de planos de aula. Contudo, pelo fato de todos os docentes serem alunos de Letras, cabe ponderar que entre eles haja a partilha de determinados conhecimentos teóricos e pedagógicos, como das abordagens de ensino de línguas que consideram as questões contextuais e culturais no processo de ensino e de aprendizagem e que historicamente são adotadas por cursos de idioma alinhados com essa perspectiva. Como exemplo, podemos citar a Abordagem Sociointeracional, baseada em Vigostski, e a Pedagogia crítica, de Paulo Freire. 
Compartilha-se, também, uma conscientização sobre os objetivos principais do curso, que é o ensino da língua com foco na modalidade oral, nas habilidades de compreensão e expressão oral.

Não há, entretanto, uma metodologia única compartilhada ou aplicada, nem obrigatória. Faz parte da autonomia dos professores elaborarem suas oficinas a partir da sensibilidade em relação ao contexto de ensino e de aprendizagem e, também, a partir dos seus conhecimentos teóricos e das discussões e reflexões que se constroem nas reuniões do projeto.

(iv) Plano de aula: sabendo que há uma discordância entre teóricos sobre o que deve constar ou como deve ser um plano de aula, pontuamos que temos dois instrumentos importantes para o planejamento e para a avaliação das aulas: o plano de aula e o relatório de aula.

O plano de aula, assim como a metodologia, é de livre escolha e criação dos professores, os quais têm a responsabilidade dessa elaboração e do compartilhamento com o grupo. Assim, não há um modelo para engessar esse trabalho, mas sim princípios e objetivos compartilhados por todos os participantes, os quais mencionamos anteriormente. De modo geral, o que cabe pontuar nesse momento é aquilo que há no PLAc e que se difere de outros contextos de ensino: com o tempo, observamos a necessidade de um plano de aula versátil, aberto a mudanças de conteúdo e de estratégias de ensino - um plano que prevê o replanejamento - tendo em vista, mais uma vez, que a turma pode ser composta por alunos que frequentam as oficinas há uma longa data e/ou por alunos recém chegados no Brasil e que nunca estudaram a língua portuguesa.

Por sua vez, o relatório de aula é feito a partir de um mesmo modelo, composto por um roteiro com o nível, duração, número de alunos, momentos da aula, objetivo(s), procedimentos e materiais utilizados, problemas antecipados e possíveis soluções para eles. Nesse relatório, nos preocupamos em descrever os momentos da aula para que todo o grupo possa ter ciência do que ocorreu em sala, além de servir de base para a nossa reflexão e avaliação da prática pedagógica aplicada.

(v) Gerenciamento de sala de aula: diz respeito ao monitoramento da fala do professor, ao gerenciamento do uso da língua-alvo - língua portuguesa - e das línguas maternas dos alunos em sala de aula, e ao gerenciamento do espaço físico da sala de aula. No planejamento de aula, prevemos que os professores devem dar prioridade ao uso da língua portuguesa, mas que em alguns momentos ele pode sim recorrer a uma língua franca ou à língua materna do aluno, caso ele a domine. Ocorre que as turmas podem ser linguisticamente heterogêneas e nem sempre os professores sabem todos os idiomas ali praticados.

O tipo de linguagem utilizada por parte do professor é menos monitorada e com mais abertura ao registro informal, com utilização da linguagem cotidiana. Nesse gerenciamento, há uma pretensão de se criar um ambiente mais natural, em que os alunos tenham contato com a língua portuguesa de fato falada na região onde residem. Essa postura com o trato da linguagem é relevante, pois abre caminho para que, a partir do que se fala e se ouve ali, durante as oficinas, os alunos já se sintam confortáveis para tirarem dúvidas sobre o que está sendo dito (vocabulário, expressões, palavras ditas muito rápidas e que se aglutinam, partículas, pronomes, etc.).

Ainda em relação ao gerenciamento das línguas em sala de aula, é dada aos alunos a liberdade de utilizarem as suas línguas maternas. Assim, os alunos mais experientes na língua portuguesa 
também dão suporte aos que sabem menos, falando em sua língua materna, e contribuem para prosseguimento do ensino e da aprendizagem.

Por fim, no quesito gerenciamento do espaço físico, nota-se que o professor se posiciona mais à frente, próximo ao quadro, e os alunos costumam ficar sentados em círculos. Essa disposição contribui para o contato e o diálogo entre os colegas e para uma melhor visão uns dos outros, considerando que é comum realizarem atividades de conversa, onde todos precisam se ater a quem tem o turno de fala.

\section{CONSIDERAÇÕES FINAIS}

Como apresentado até aqui, todo o planejamento de aula é orientado por uma abordagem de acolhimento linguístico útil e essencial para a promoção da integração e da inclusão da comunidade em contexto de migração forçada na sociedade local, visando ao seu acesso aos direitos básicos, como trabalho, moradia e educação. Se assim não o fosse, esse curso e esse projeto não existiriam, pois a oferta tradicional e mercadológica de cursos de línguas já é um serviço presente na região do Distrito Federal.

Retomando Almeida Filho (1996), a necessidade de um planejamento pode ocorrer em diferentes situações educacionais como em situações novas para as quais o planejamento é um pré-requisito para a implementação de um processo de ensino-aprendizagem. Por essa razão, o curso de português como língua de acolhimento, aqui analisado, apresentou vários elementos que caracterizam o seu planejamento, tanto no nível macro - planejamento de curso - quanto no nível micro - planejamento de aula.

A descrição dos elementos que constituem o planejamento do PLAc nos revela a sua importância e nos chama a atenção para a necessidade de se elaborar políticas linguísticas especializadas, como as destinadas aos imigrantes e aos refugiados. Nesse sentido, nota-se que o planejamento do ensino de português na perspectiva do acolhimento se caracteriza como uma política pública inclusiva, cujos pilares norteadores são partilhados por seus agentes e apoiadores.

Observa-se, também, que a elaboração e a implementação do PLAc, no âmbito do Projeto analisado, contou com importantes parcerias, como o Instituto de Migração e Direitos Humanos - IMDH e o DFTrans. Há indícios, também, de que a Secretaria de Estado de Educação do DF, como um poder representativo do Estado, também passou a estar compromissada com a política de cooperação e acolhimento linguístico e social de imigrantes e refugiados.

Diante desses dados, revela-se a importância da participação colaborativa de agentes públicos e privados, bem como da sociedade civil no planejamento de uma política pública. Não distante desse aspecto, parte das dificuldades encontradas no planejamento e na implementação do PLAc pode estar atrelada à divergência de perspectivas políticas e administrativas entre os agentes, a exemplo da decisão unilateral do DFTrans em finalizar a parceria com o Projeto. Por um lado, essa decisão nos demonstra que esse órgão não partilha da mesma perspectiva política e administrativa com a qual o Projeto, o IMDH, o ACNUR e o Conare trabalham - a perspectiva do acolhimento e da cooperação -, por outro lado, nos atenta para o fato de que burocracias e divergências internas podem fomentar finalizações de parcerias e de projetos.

Este trabalho pretendeu levantar a discussão e a reflexão do PLAc como uma política, constituída por vários atores, e demonstrar como o seu planejamento é importante, necessário e justi- 
ficado por suas especificidades. Sem dúvidas, a partir de mapeamentos e atlas da migração, como os já existentes em São Paulo e em Minas Gerais 5 , é possível identificar as localidades onde há a presença de migrantes advindos da migração forçada e planejar ações e políticas públicas inclusivas voltadas ao atendimento dessa comunidade.

\section{REFERÊNCIAS}

ALMEIDA FILHO, J. C. A abordagem orientadora da ação do professor. In: (Org.). Parâmetros atuais para o ensino de português língua estrangeira. Campinas, SP: Pontes, 1997, p.13-28.

ALMEIDA FILHO, J. C. (Org.). Fundamentos de Abordagem e Formação no Ensino de PLE e de Outras Línguas. Campinas, SP: Pontes Editores, 2011.

ARANTES, P. C. C.; DEUSDARÁ, B.; BRENNER, A. K. Língua e alteridade na acolhida a refugiados: por uma micropolítica da linguagem. Fórum linguística. v. 13, n. 2, abr./jun. 2016.

BARBIER, R. A escuta sensível na abordagem transversal. In: BARBOSA, J. (Coord.). Multirreferencialidade nas ciências e na educação. São Carlos: Editora da UFSCar, 1998.

BARBIER, R. A pesquisa-ação. Brasília: Lỉber Livro, 2007.

BRASIL, Lei de Migração n. 13.445, de 24 de maio de 2017. Dispõe sobre os direitos e os deveres do migrante e do visitante, regula a sua entrada e estada no País e estabelece princípios e diretrizes para as políticas públicas para o emigrante. Diário oficial da União: Brasilia, 2017. Disponível em: http://bit. ly/2QPXoGR. Acesso em: 04 fev. 2019.

BRASIL, Lei do Refúgio n. 9.474, de 22 de julho de 1997. Define mecanismos para a implementação do Estatuto dos Refugiados de 1951, e determina outras providências. Diário oficial da União: Brasília, 1997. Disponível em: http://bit.ly/37lQE90. Acesso em: 04 fev. 2019.

UNESCO, Declaração Universal dos Direitos Humanos, de 10 de dezembro de 1948. Disponível em: http://bit.ly/36L7SNa. Acesso em: 04 fev. 2019.

CALVET, L. J. As políticas linguísticas. Tradução: Isabel de Oliveira Duarte; Jonas Tenfen; Marcos Bagno. Campinas, SP: Parábola Editorial: IPOL, 2007. 164p.

CANCHERINI, A.; FRANCO, M. A. S.; PONTES, R. A. F. A escuta sensível como instrumento metodológico na formação inicial de docentes. CAMINE: CAMINHOS DA EDUCAÇÃO, v. 4, p. 1-15, 2012.

CONARE. Refugiados e Conare. Disponível em: http://bit.ly/2QMqR4f. Acesso em: 20 jan. 2019.

COURY, P.; ROVERY, J. O idioma como facilitador do processo de integração de refugiados e imigrantes: a experiência do Instituto Migrações e Direitos Humanos (IMDH). In: Cadernos de debates refúgio, migrações e cidadania. v.12, n.12, Brasília: Instituto Migrações e Direitos Humanos, 2017, p.101-116.

EUZEBIO, U.; REBOUÇAS, E. M.; LOPES, L. P. S. Língua de acolhimento: demandas e perspectivas subjacentes ao conceito e à prática pedagógica no contexto brasileiro. In: GUIMARÃES, D. N; ANDRÉ, B. P. (Orgs.). Educação e diversidade: diálogo intercultural. RJ: Brasil Multicultural, 2018, p. 58-87.

GROSSO, M. J. R. Língua de acolhimento, língua de integração. Horizontes de Linguística Aplicada, v. 9, n. 2, 2010, p.61-77.

INTERNATIONAL ORGANIZATION FOR MIGRATION. World Migration Report 2013: migrant well-being and development. Disponível em http://bit.ly/2FGTEAL. Acesso em 19 jan. 2019.

LOPES, L. P. S. O estatuto linguístico de segunda língua e de língua estrangeira do português brasileiro: consonância ou dissonância entre discurso oficial e discurso docente? Dissertação de Mestrado. Programa de Pós-Graduação em Linguística, Universidade de Brasília. Brasília, 2018, 170p.

OLIVEIRA, L. A. Aula de inglês: do planejamento à avaliação. SP: Parábola, 2015, 269 p.

4 Atlas temático Observatório das Migrações - Migrações Internacionai (UNICAMP / SP): http://bit.ly/2TgU8pm.

5 Atlas Digital da Migração Internacional em Minas Gerais (PUC-MG): http://bit.ly/35JuR9N. 
PAIVA, V. L. M. de O. Teoria Sociocultural. In: Aquisição de Segunda Língua. São Paulo:

Parábola, 2014.

RAJAGOPALAN, K. Política linguística: do que é que se trata, afinal? In: NICOLAIDES, C.; SILVA, K. A.; TILIO, R.; ROCHA, C. H. (Orgs.). Política e políticas linguísticas. Campinas, SP: Pontes Editores, 2013, p.19-42.

RAJAGOPALAN, K. O professor de línguas e a suma importância do seu entrosamento na política linguística do seu país. In CORREA, D. A. (Orgs.). Política linguística e ensino de língua. Campinas, SP: Pontes Editores, 2014, p.73-82.

RAMOS, A. A. L. Princípios teórico-metodológicos em práticas pedagógicas de português brasileiro como língua adicional - PBLA. In: SILVA, F. C. O.; VILARINHO, M. M. O. (Orgs.). O que a distância revela volume IV: diálogos em português brasileiro como língua adicional. Brasília: Universidade Aberta do Brasil, UAB, UnB, 2017, p.19-50.

VIANA, N. Planejamento de cursos de línguas - pressupostos e percursos. In: Almeida Filho (Org.). Parâmetros atuais para o ensino de português língua estrangeira. Campinas, SP: Pontes, 1997, p.29-48.

Recebido em 17/9/19 Aceito em 5/11/19 